\title{
Challenges of postgraduate research: case of developing countries
}

\author{
Stephen M. Mutula' \\ School of Sociology and Social Studies, Information Studies Programme, University of Kwazulu Natal \\ Private Bag X0I, Scottsville, Pietermaritzburg, 3209, South Africa \\ mutulas@ukzn.ac.za
}

Received 12 December 2009

Accepted 23 July 2011

\begin{abstract}
Postgraduate research is a form of study offered by a university or an institution of advanced learning. The emphasis of postgraduate research is on developing systematic skills of investigation in research process. It is not necessarily aimed at producing ground breaking innovation or extending knowledge as is commonly perceived. Most postgraduate research involves basic and to a lesser extent applied and/or collaborative research. This article is an offshoot of a paper presented at the Department of Information Studies (University of Zululand, South Africa) Annual Conference from 10-II September 2009. The article discusses the challenges of postgraduate research with special reference to universities in Africa. The author proffers suggestions on minimizing the challenges of postgraduate research faced by university institutions in Africa.
\end{abstract}

Keywords: postgraduate programmes, research utility, research productivity, research capacity, research supervision, university education, Africa

\section{Introduction}

Universities the world over are recognised as places where knowledge generation, scholarship and innovation are advanced. Postgraduate programmes are considered conduits through which universities develop research capacity and also generate high skills needed for a functional economy and in addressing complex issues such as global financial recessions, climate change, poverty alleviation and more. Postgraduate research takes various forms but generally requires those admitted to such programmes to have completed bachelor's degree or a diploma. Consequently, nomenclatures such as postgraduate diploma, master's degree, master of philosophy, $\mathrm{PhD}$ or higher $\mathrm{PhD}$ are now commonly encountered in tertiary education systems. Postgraduate qualifications may be classified as traditional/ academic or professional degrees. The traditional postgraduate qualifications tend to be generic while professional ones reflect a deeper understanding of a discipline (Postgraduate Research 2009). The requirements for admission into postgraduate programmes will vary from institution to institution or from one jurisdiction to another. For example, in Australia, Canada and the United States admission into a $\mathrm{PhD}$ programme may require a prerequisite study over and above the graduate study. Such prerequisite may take different forms such as master's course work, distinction in a bachelor's degree or a distinguished academic track record. Another emerging trend is to award a doctorate degree on the basis of evaluation of one's research and publication track record in a given field. Within Africa, the University of Ghana practices this form of doctoral award. As to the duration of a given postgraduate qualification, this tend to vary from institution to another within the same or/and different jurisdictions. For example, a full time master's degree may last between 9 to 12 months (e.g. UK, South Africa) or up two years or more (common practice in Africa) while part time master's degree depending on institution or jurisdiction may take four years or even more. For PhD full time study, the duration varies between two and six years with average duration being four years (Mouton 2007).

In general, post graduate research is not intended to yield ground breaking results, discovery or innovation (Postgraduate Research 2009). It is actually an apprenticeship into mastering systematic research process. Ticinch (2006) points out that the objective of postgraduate research is not to make a breakthrough invention or indeed a major scientific discovery, but rather a mechanism by which graduate students learn how to undertake a systematic investigation, founded upon work built by peers in the field and then to extend the current state of knowledge. Emphasis is placed on systematic investigation than the level of extending current state of knowledge. The doctorate recipient in the past and still today is largely expected to assume some form of teaching role premised on the concept doctor (Latindocere meaning to teach).

As to the implementation and awards of postgraduate qualifications, there are variations. For example, a study for a $\mathrm{PhD}$ results in a thesis which has to be assessed by independent experts in the discipline. Some institutions insist that a thesis especially at PhD level must be defended in a viva-voce oral examination where candidates present their research

I. Stephen M. Mutula (PhD) is an Honorary Research Fellow and Professor in the Department of Library and Information Science, University of Zululand, South Africa 
before an expert panel. Likewise titles arising from completion of postgraduate study vary. For higher level research, the qualification name tends to be general (with some exceptions) while for lower level qualifications (first degree, etc) the qualification carries with it the discipline name (Postgraduate Research 2006). For example, at bachelor's level it is common to include the discipline in the qualification award i.e. BSc (Chemistry), but a corresponding degree would be an MSc (without specific discipline). Similarly, at doctoral level, the degree would simplify be PhD with no discipline stated. The higher levels of postgraduate qualification represent generic mastery of research techniques. In professional doctoral qualifications, where a demonstration of depth of research knowledge of discipline is the main outcome, the discipline is included i.e. doctor of business, doctor of engineering, etc. In some universities especially in developed world, candidates are awarded higher doctorate which is a demonstration of substantial contribution to their discipline through research. Usually such awardees shall already have a PhD. Higher doctorates carry the title of the discipline (Postgraduate Research 2006).

Kearney (2008) observes that research degrees continue to denote advanced study in a chosen discipline with a view to pursuit of an academic career. In this regard, expertise in research methodology and investigative skills are acquired. There is a growing demand for master's and doctorate degrees related to a specific field of professional activities such as business studies or administration. These degrees are sometimes referred to as taught qualifications which may be taken concurrently with workplace activity. They involve some degree of research on the part of faculty and the students. This trend is common in Europe and OECD countries. In this form of postgraduate programmes, demand is driving supply with national education systems being forced to adapt to this changing paradigm (Postgraduate Research 2006). This demand has resulted in the emergence of new providers beyond the traditional market for higher education such as the United Kingdom, United States, Australia, New Zealand, Germany, France, etc. The traditional markets for higher education are now establishing off shore campuses to tap into new market occasioned by the paradigm shifts in postgraduate degrees in such places as East Asia, Eastern Europe, and the Gulf States where there is great demand for English, computer science, business studies, etc.

The purpose of postgraduate research is to among other things (Mutula 2009):

- Test assumptions/observations;

- Provide theoretical framework to understand the information reported by individual scholars;

- Create new knowledge; and

- Carry a responsibility to disseminate and apply the results of a research activity.

Various types of research exist namely: basic, applied/action, collaborative, contract and sponsored. Basic research seeks to create new knowledge and is not directly related to technical or practical problems (e.g. a study conducted to analyze online public access catalogue use). Applied/action research seeks to solve problems by developing solutions and recommendations that can be used to improve practices (i.e. conducting a study on how information systems can be used for poverty reduction). Collaborative research is jointly conceptualised and/or funded between a university and a partner. Contract research occurs when a request is made by industry or a government agency for a specified research project to be carried out with identified aims and objectives. Finally, sponsored research is when funding is based on proposal that is submitted on a competitive basis. Most postgraduate research falls within the realm of basic but less on applied and collaborative research. By and large, applied, collaborative, contract and sponsored research tend to be undertaken largely by faculty (because of their proven expertise) but less by postgraduate students.

Post graduate research is a form of apprenticeship taken under the supervision of senior faculty. The faculty involved in supervision of post graduate research must have adequate skills to effectively play the role of promoter/supervisor. Such skills include but are not limited to (University of South Africa \& National Research Foundation 2007):

- Guiding postgraduate students towards sound preparation of research;

- Methodological choices;

- Documenting and publishing research;

- Maintaining both supportive and professional relationships; and

- Helping candidate challenge dominant ideas, redefine a problem, and develop a theory.

The Task Group on the Future of Graduate Research Supervision at the University of Botswana (University of Botswana 2009) in a survey of postgraduate students at the university, enlists reasons that were given by students as motivation for pursuing graduate studies that include: advancing or improving one's academic qualification in order to become more competitive on the job market, a requirement for promotion by the employer, enhancing personal career life, developing academic credentials, expanding intellectual knowledge and gaining deeper understanding of one's profession or subject 
of study, desire to contribute to research and applicable science knowledge. It would seem, the perception about the role of postgraduate study is not necessarily research but motivation for better career prospects.

For students planning to pursue postgraduate studies/research, the choice of the institution that will meet their expectation is critical. The Task Group on the Future of Graduate Research Supervision at the University of Botswana (University of Botswana, 2009) found that in the choice of the institution, students were motivated by:

- Reputation of the University/programme;

- Quality of education at the university;

- Accessibility to postgraduate education;

- Affordability of fees;

- Familiarity with the system of the institution;

- Level of financial support offered;

- Facilities available;

- Diversity of postgraduate programmes;

- Availability of skilled faculty; and

- Provision of scholarship and grants.

\section{Enhancing postgraduate research}

The research quality of any university is perceived in terms of among other criteria excellence of library facilities, quality of ICT infrastructure, supportive institutional framework, qualified staff, diversity and strength of postgraduate programmes, level of research funding, links with international scholarly community and industry, provision of grants for young researchers, mentorship programmes, integration and use of ICT in teaching and research, availability of digitized local content, functional institutional repository, number of international students and faculty, quantity of collaborative and multidisciplinary research and more (Mutula 2009).

To further enhance the quality of research, universities tend to build seminars and workshops into postgraduate programmes covering such areas as time management, project management, business communication, oral examination, thesis writing, responsible conduct of research, formatting research essay, citing and referencing techniques, using archival sources, content analysis, critical discourse analysis, ethnographic research, action research, quantitative / qualitative research, literature review, basic and applied research (University of Botswana 2009).

The Department of Library and Information Science at the University of Zululand has put in place research practices that are worth of note. The research output in the department is largely attributed to collaboration and joint authorship between staff and postgraduate students. Besides, postgraduate students are subject to rigorous vetting prior to being offered admission into postgraduate programmes. Students are also guided in selecting their research topics and the department also provides leadership in setting the research agenda based on niche areas such as social informatics, informetrics, user studies, etc. Regular reporting of progress of students' research and defined schedules acts as a powerful feedback control and tracking tool. The practice of team supervision and joint authorship between faculty and students help accelerate research output (Mutula 2008). The other positive attribute of the research portfolio of DLIS (UZ) includes; use of ICT in teaching; documentation and reporting research output through annual reports, and conference proceedings published online. Besides, research project is included in the undergraduate curriculum. Furthermore, engaging postdoctoral/visiting faculty contribute to enriching robustness of the postgraduate programmes. The staff in Department is however constrained by heavy teaching loads carried by faculty and the large numbers of students at undergraduate level that need remedial academic support (Mutula 2008).

\section{Challenges of postgraduate research}

Postgraduate education in general and postgraduate research in particular faces challenges of demand, supply, quality and returns on investment both for service providers and clientele (Kearney 2008). As already pointed out, postgraduate research challenges are not confined to developing countries alone but also to the developed world. However, countries of the developed world such as German, Australia, Canada, the United States, and New Zealand have made remarkable progress in addressing research challenges that are currently faced by most universities in Africa (Scholtz 2007). Research in most universities in Africa is hardly coordinated. Often, variations exist in approach and even in fulfillment of requirements for postgraduate research programmes not only in different universities but also in the same university in such areas as the number of years to complete masters or doctoral degree for full as well as part time students. Research and development in third world countries has negatively been affected following the shift of focus in financial support from higher to basic education by the World Bank and IMF during the 1980s and part of 1990s. This shift of focus by the Breton woods institutions is exacerbated by low student completion rates in postgraduate programmes. It takes on aver- 
age 6-8 years to complete a PhD in most African Universities as a result of inadequate resources and bureaucracy in the approval process involving departments, faculties and universities (Manyika and Szanton 200 I).

In South Africa the transformation of technikons into universities of technology created serious research skills shortage. Lamprecht (2008) pointed out that South African government and the public are dissatisfied with the quality of graduates from universities with regard to the nature and appropriateness of their qualifications, training and competitiveness in some fields. A former Minister of Education in the Mbeki government, Naledi Pandor noted that the drop-out and through-put rates in the universities were bad not only because of poor school education but also due to poor teaching at the universities (Badat 2008; Higher Education Working Group 2005). Similarly, the Southern Africa Regional Universities Association (2008) noted that there was $60 \%$ university dropout rate in South Africa. The students affected were mainly from poor families who dropped out before completing their studies on account of pregnancy, finding campus life too boring and structured; social and personal problems; having to care for sick relatives, peer pressure, and more. Biermann and Jordaan(2008) carried out a study on research skills in South African universities and found that students at graduate level experienced a large array of problems in writing, searching and presenting original work. In particular, students in their first year were exposed to a culture of copying especially within computer programming fields. They also found that the status of research at the universities of technology was poor because of the scarcity of research expertise, inexperienced supervisors, and supervisors working in fields that differed from their specialisations. This situation resulted in low research outputs, and generally discouraged students who would wish to continue with their postgraduate studies.

Botha and Simelane (2007) observed that in most South African universities, research was neither published nor digitised, making it largely inaccessible. The University of Stellenbosch added its voice to this issue in the 2007 annual report pointing out that the University faced challenges related to student access and success, backlog with regard to facilities, equipment and other capital, decreasing government subsidies thus, impelling universities towards far reaching structural changes. Moahi (2007), in a study of library and information science research in Botswana between 1980 and 2006, found that most research was of a descriptive nature and lacked the empirical rigor to make any impact on national development. She noted that the country has seen little cross-disciplinary research endeavors, and more often than not, no collaborations between practitioners and academics occurs. She added that, research in east, central and southern Africa has also not been informed by a research agenda in spite of the fact that increasingly, now than ever before, the complex global environment demands academics to work with others across disciplines to address emerging priorities that cut across traditional disciplinary boundaries.

Oosterlinck (n.d.) observes that most universities have a structure which is relatively hostile to interdisciplinary developments against most of society's major problems requiring an interdisciplinary approach. Often, academic research suffers because more time is spent on data collection while, little time is left for analysis and robust reporting. Consequently, findings are often not clearly presented and explained for the end user to understand making such results of little practical value and application. It is also not uncommon to find students wanting to cover so many objectives in a single project. In such cases, elaborate data collection, analysis and reporting is needed, making it difficult to relate one objective to another. Furthermore, such research will more often than not lack a clearly defined focus. Though there is no unanimity on the number of objectives that is suitable for a research project such as a dissertation, 3-5 is considered realistic

Zakri (2006) considers three main challenges affecting research process. These challenges include: research capacity, research productivity and research utility. Research capacity relates to availability of research facilities, and availability of trained human resources capable of doing research. Research utility focuses on relevance of the research outcomes to national development agenda or priorities. Since national or international development is a cross disciplinary subject, research should try and involve researchers across different disciplines otherwise, the outcome would be of limited value. Research product refers to optimisation of resources available to enhance quality of research. Zakri notes that universities in developing countries are not fully geared towards solving development related problems. The study found gaps in linking research with development priorities. It found that there are weak linkages between knowledge producers and knowledge users and between knowledge production and innovation.

Postgraduate research process carried out to meet requirements for an award of a qualification faces other unique challenges. A study carried out among LIS schools in east, central and Southern Africa on the supervisor-supervisee relationship among postgraduate students revealed the following (Mutula 2009):

- Delays in receiving feedback;

- Lack of supervision guidelines;

- Poor supervision - i.e. no schedule for meetings, no records of discussions;

- No mechanism for redress (40\%);

SA JnI Libs \& Info Sci 20I I, 77(2) 
- Supervisors always too busy to meet students;

- Lack of support for students from non-LIS disciplinary backgrounds; Inadequate preparation for postgraduate study;

Heavy teaching loads for faculty; and

Unnecessary administrative assignments.

Other challenges that were identified in this study included: poor quality of students admitted, students delays in submitting their work, and inability of students to balance between job and studies. In particular, the respondents said they consulted with their supervisors, once a week $(28 \%)$, once in four weeks $(16 \%)$, once in two months (16\%), once in more than two months (8\%), 3 to 4 times a year (4\%), no time specified or it depends on supervisor ( $16 \%)$, by mutual agreement $(16 \%)$. Most respondents preferred one supervisor $(56 \%)$, while those who preferred more than one supervisor were (32\%). Those who preferred one supervisor were motivated by the need for one supervisor to cover the absence of the other, or to get wide range of opinion, and also for adding value to research process. Whereas some supervisors guided students on what sources to use (64\%) others (32\%) did not. Those candidates who preferred one supervisor said; if a supervisor is well-versed in the subject, there is no need for more supervisors. They noted that with more than one supervisor, there are delays in getting feedback as one has to wait for both parties to agree. And often there are conflicting views among opinion with more than one supervisor thus, confusing students. The study by Mutula (2008) also revealed the following challenges in research supervision; delay in approving topic (44\%), unnecessary delay in getting feedback (36\%), supervisor non-availability (36\%), difficulty of striking balance between job and school (44\%), intimidations by supervisors $(28 \%)$, difficulty in finding relevant literature $(28 \%)$, and delays from external examiners (24\%).

Similarly, the Task Group on the Future of Graduate Research Supervision at the University of Botswana (University of Botswana 2009) found that timely completion rate of postgraduate degrees at the University of Botswana was low and varied from 14\%-37\% of the total number of students registered for masters, M. Phil and PhD degrees. Factors affecting completion rate were found to include: availability/accessibility of supervisor, commitment on the part of both supervisor and candidate, poor design of work plan and infrequency of meetings between supervisor and candidate. Delays in completing postgraduate studies were attributed to lack of facilities-equipment, software, chemicals; difficulty of combining study and job (for part time students), inadequate financial support, lack of adequate preparation of students at undergraduate level for research, inadequate guidelines for writing thesis/dissertations, inadequate supervision, change of project focus midway, etc. From the perspective of supervisors, delays in completing postgraduate projects were due to laziness on the part of candidates, heavy teaching loads for faculty, poor research culture, inadequate institutional support, lack of research skills on the part of students, some students expecting supervisors to do the work for them, red-tape in examination process, and delays in securing research permits.

Among the recommendation reached to alleviate the problems of research cited above include:

- Staff supervising students should be given less teaching loads and other responsibilities;

- Thesis writing should be optional (32\%);

- Guidelines for supervision should be provided (40\%);

- Schedule for meetings between students and promoters should be defined and agreed upon (32\%);

- Feed back on submitted work should be provided within a week (32\%);

- Students should be allowed frequent meetings with HOD to discuss progress and behaviour of errant supervisors (28\%);

- Matching student topic and supervisor skill (36\%); and

- External examiners should be carefully selected to ensure they can examine theses in time.

\section{Opportunities for postgraduate research in Africa}

Despite the challenges facing postgraduate research especially in Africa, there is an emerging gleam of hope. Some governments are recognizing the importance of research and are increasing support for research to universities. South Africa now spends about $1 \%$ of its gross domestic product on R\&D. The international support for research is also growing from such bodies as Overseas Development Agency (ODA) which provided \$105.5 billion in 2005 and was expected to increase this support to $\$ 130$ billion by 2010 (Zakri 2006). Postgraduate students are now than before freely accessing hundreds of scientific and professional journals, papers, documents, encyclopedias, reports, presentations and lectures from such services as African Journals Online (AJOL). This represents a considerable progress in comparison with the situation prevailing only a few years ago. Several bibliographic networks or digital libraries such as SABINET (Southern Africa), Ain Shams University Network (ASUNET) in Egypt, African digital library and African online digital library have made possible access to such resources as digitized theses and dissertations, e-books, and databases possible. 
Moreover, several universities in Africa like their counterparts in the rest of the world are increasingly using their webbased online public access catalogues (OPACs) as gateways not only to information outside their libraries but also to their own locally digitised content. For example, at the University of Botswana library, the OPAC is used to provide access to among other resources, digitised full-text past examination papers, aggregated journal content, and digital repository. At the University of Pretoria in South Africa, the library provides access to its institutional repository containing locally generated content (Pienaar \& Daventer 2007). Rhodes University also in South Africa publishes electronic theses and dissertations (ETD) and makes them available on the university intranet. Overall, digital education content is increasingly being generated in Africa as, many tertiary institutions especially, universities turn to e-learning. Such digital content consists of variety of learning materials that may vary from basic text to multimedia such as: assignments; reading lists, course notes, course syllabi, course objectives and external content links.

Libraries are also transforming their print collections into electronic formats through digitization or subscription to ejournals with or without print alternatives as a strategy to make them more accessible and to enhance resource sharing (Youngman 2007). Scholars and publishers are now required to make their publications available through open access so that they can be easily and widely accessed (Association of Research Libraries 2006). These tools are needed to ensure that scholars involved in research know what their counterparts are doing elsewhere thus, enhancing collaboration, sharing of knowledge and best practices.

\section{Conclusion}

This article has demonstrated the several challenges faced by most African universities that hamper effective postgraduate research. Most countries on the African continent do not have funding for postgraduate research. Consequently only a few students are able to access higher degrees. Universities must on their own try and find alternative ways of generating third stream funding. Besides, diversifying research efforts into areas considered niche rather than duplicating what other universities are already doing is important. Such niche research areas would form the basis for postgraduate student dissertations as well as for joint research between faculty and students. The niche research areas should be aligned with national development priorities and international agenda with students projects demonstrating relevance to such priorities. Investing in open access and institutional repositories (departmental, national, academic, specialized, etc) as well as capacity building through training of researchers would enhance research environment. Research should be coordinated in order to avoid duplication but instead make optimal use of the resources available. Information literacy impartation to postgraduate students is important to develop skills needed to seek, organize and apply information. Students' theses should be digitized and made available online to make them more accessible 24/7. In addition, it is important for universities to work closely with industry in research endeavours in order to address market needs. Improving the quality of undergraduate's programmes would help lay a strong foundation for postgraduate programmes.

The other actions that our universities need to implement in order to enhance the capacity of research environment include: offering faculty-wide postgraduate programs (rather than departmental-based degree), improving capacity through collaboration and partnership to facilitate skills and technology transfer, ensuring that research is tailored to help address poverty and make life much easier.

\section{References}

Association of Research Libraries. 2006. Digital scholarship. [Online]. http://www.createchange.org/digitalscholarship.html. (Accessed 28 September 2007).

Badat, S. (2008). 1990-2003: Goals, Policy Initiatives and Critical Challenges and Issues. [Online]. http://www.foundationpartnership.org/pubs/southafrica/index.php?chap=chap/\&sub...[Accessed 9 September 2008].

Bierman, E. \& Jordaan, M.C.E. 2007. Developing applied research skills in 4th year students using e-learning: a case study. Paper Presented at the WWW Applications Conference held from 5-7 September 2007 at the University of Johannesburg, South Africa.

Botha, C.T and Simelane, S. 2007. The Influence of e-learning on students success rate in human resource development. Paper Presented at the WWW Applications Conference Held from 5-7 September 2007 at the University of Johannesburg, South Africa.

Higher Education Working Group (2005). The Challenges Facing Higher Education in South Africa: Discussion Points. [Online]. http://www.thepresidency.gov.za/docs/pcsa/social/challenges.pdf [Accessed I I September 2008].

Lamprecht, S. 2008. Science and technology fall by the wayside. Daily Mail, September 2, 2008, 18

Kearney, M.L. 2008. The role of postgraduate education in research systems. Proceedings of UNESCO/DCU Workshop on Trends in Post -Graduate Education, 5-7 March 2008, Dublin City, Ireland.

Manyika, S. \& Szanton, D.L. 200 I. PhD Programs in African universities: current status and future prospects - a report to the Rockefeller Foundation. Berkley: University of California, Berkley.

SA Jnl Libs \& Info Sci 20II, 77(2) 
Moahi, K. 2007. Library and Information Science research in Botswana: an analysis of trends and patterns. World Library and Information Congress: 73 ${ }^{\text {rd }}$ IFLA General Conference and Council, 19-23 August 2007, Durban, South Africa. [Online]. http://www.ifla.org/iv/ifla73/index.htm. (Accessed 2 October, 2007).

Mouton, J. 2007. Reflection of the current throughput challenges in South African Higher Education. Address Delivered to the Postgraduate Research Indaba at the University of South Africa 20-22 February 2007.

Mutula, S.M. 2008. Farewell speech as a sabbaticant at University of Zululand Delivered at DLIS Retreat Held on 25 November 2008, at Tuzi Gazi Conference Centre - Richards Bay

Mutula, S.M. 2009. Building trust in supervisor-supervisee relationship: case study of east and southern Africa. Paper Presented at the Progress in Library and Information Science in Southern Africa (PROLISSA) Conference at the University of South Africa (UNISA) on 4-6 March 2009

Oosterlinck, A. (n.d.). Knowledge management in post-secondary education: universities. [Online]. http://www.oecd.org/ dataoecd/46/2 I/207492I.pdf. (Accessed 8 September 2008).

Pienaar, $\mathrm{H}$ and Deventer, M. 2007. Investigating the need for a virtual research environment (VRE) for malaria research in the South African context: a South African malaria initiative [Online] http://www.acgt.co.za/sami/index.html [site accessed 9 May 2008].

Postgraduate Research 2009. Wikipedia [Online]. http://en.wikipedia.org/wiki/Postgraduate_reserach. (Accessed 7 September 2009).

Scholtz, B. 2007. International experience in research capacity development. Keynote address delivered at the Postgraduate Research Indaba at the University of South Africa 20-22 February 2007.

Southern Africa Regional Universities Association. 2008. Higher Education in the News, I(6): 24 February-I March.

Toncich, D.J. 2006. Key factors in postgraduate research: a guide for students. Brighton, Australia: Christobel Engineering

University of Botswana. 2009. Report of the Task Group on the 'Future of Graduate Research Supervision at University of Botswana'. Gaborone: School of Graduate Studies, University of Botswana.

University of South Africa \& National Research Foundation. 2007. Postgraduate Supervision Conference. [Online]. http:// www.postgraduate2009.co.za. (Accessed 8 September 2009).

Youngman, F. 2007. Opening Speech- Digital Scholarship Conference held on 12-I3 December 2007, at the University of Botswana Library Auditorium.

Zakri, A.H. 2006. Research universities in the 2 I st century: global challenges and local implications. Global Keynote Scenario at the UNESCO Forum on Higher Education, Research and Knowledge: Colloquium on Research and Higher Education Policy, November 29-December I, 2006, Paris. 